\title{
Skill Complementarity and the Dual Economy
}

\author{
Asger Moll Wingender* \\ University of Copenhagen
}

February 9, 2012

\begin{abstract}
A typical developing country have a large and unproductive agricultural sector that coexists with a smaller and more productive modern sector. Such dualism has often been ascribed to frictions unique to low income countries. This paper shows that it can arise endogenously in a frictionless model if skilled workers are in short supply and if the complementarity between skilled and unskilled labor in production differ across sectors.
\end{abstract}

\section{Introduction}

A growing body of empirical papers suggests that one-sector models are inadequate to explain the income gap between developed and developing countries. Sectoral productivity differences within poor economies are as important for global inequality as cross country productivity differences in modern industries like manufacturing. The main reason is that low income countries tend to be dominated by large traditional sectors (e.g., agriculture and informal services) with productivity levels that trails the smaller modern sector. Chanda and Dalgaard (2008) and Vollrath (2009b) reckon that such dual economy structure, unique to developing nations, explains as much as 80 percent of cross country variation in aggregate TFP. Caselli (2005),

${ }^{*}$ Contact: amw@econ.ku.dk. I thank Carl-Johan Dalgaard for useful comments and suggestions. 
Temple (2005), Temple and Wößmann (2006), Restuccia et al. (2008), McMillan and Rodrik (2011), Gollin et al. (2011), among others, provide similar conclusions for labor productivity. ${ }^{1}$

A vast theoretical literature has evolved around this empirical result. The dual economy is often seen as a mirror image of inefficient factor markets, externalities, or other distortions. ${ }^{2}$ While such frictions undoubtably are an important part of reality, they are hard to measure and likely to have different sources in different countries. To paraphrase Tolstoy: undistorted economies are all alike; every distorted economy is distorted in its own way. A fully competitive dual economy model will therefore be a useful benchmark in cross country comparisons. Consequently, the starting point of this paper is the question: can a model without frictions generate intersectoral productivity gaps and employment shares like those observed in the data? It turns out that the answer is yes if the complementarity between skilled and unskilled workers differs across sectors.

Both history and the reality of developing countries today confirm that agricultural production or simple services do not require a labor force with any formal education. Manufacturing and other modern industries do, in constrast, rely on some skilled workers for installing and maintaining machinery, accounting, marketing, and so on. Such workers are employed along with a relatively unskilled labor force on the factory floor. Thus, skilled and unskilled workers are more complementary in the modern sector than in the traditional sector.

Armed with this observation, I develop a simple, static and fully competitive model in which the dual economy structure is caused by a scarcity of skilled workers. The mechanism can be summarized as follows. A relatively high degree of skill complementarity in the modern sector makes the marginal products of skilled and unskilled workers there more sensitive to the skill composition of the labor force. The wage rate for educated workers in the modern sector will therefore be higher than in the traditional sector in a country with little human

\footnotetext{
${ }^{1}$ A seminal contribution is Kuznets (1971).

${ }^{2}$ Recent models based on factor market distortions can be found in Landon-Lane and Robertson (2007), Restuccia et al. (2008) and Satchi and Temple (2009). Gollin et al. (2004) and Vollrath (2009a) introduce a more subtle distortion by assuming that workers cannot work in both the modern and the traditional sector simultanously. Models with inefficient market outcomes due to externalities include Graham and Temple (2006) and Rodrik (2009).
} 
capital available. The country will consequently have all of its skilled workers employed in the modern sector, but, given their small numbers, only a few unskilled workers are needed to accompany them. A rising share of skilled workers in the population will increase the demand for unskilled workers in the modern sector, causing it to expand. At the same time will the increasing supply of skilled workers put downward pressure on their going wage rate until, at some point, pay in the traditional sector becomes competitive. The resulting flow of educated workers into the traditional sector will boost its productivity and thereby close the sectoral productivity gap. The model does in that sense explain both the dual economy and how the backward sector graduates into a modern sector as a country develops.

Despite being static, the model is in many ways related to the growing theroretical literature dealing with the transition to modern economic growth in multi-sector models. ${ }^{3}$ One important difference, however, is that economic development in this paper is pinned down by human capital rather than an unobservable productivity level. Moreover, most competitive models of structural transformation are based on a representative agent framework and are therefore unable to generate a dual economy without assuming heterogenous labor income shares. Caselli and Coleman (2001) and Lucas (2004) are notable exceptions, and are probably the closest cousins to this paper.

The paper is organized as follows. Section 2 provides a birds eye view on the empirical facts that this paper sets out to explain. The model is developed in section 3 , and section 4 calibrates its parameters to match data from the United States. Section 5 compares the predictions of the calibrated model to a cross country data set. Section 6 concludes.

\section{The Facts}

The empirical findings that motivates this paper are briefly reviewed in this section. Data is obtained from two sources. Evidence on educational attainment is from the Barro and Lee (2010) database, and McMillan and Rodrik (2011) is the source of sectoral employment and value added data. Combined, these two data sets span 34 vastly different countries in

\footnotetext{
${ }^{3}$ E.g., Hansen and Prescott (2002), Gollin et al. (2007), Strulik and Weisdorf (2008), and Lucas (2009).
} 
all parts of the world. ${ }^{4}$ Moreover, data is available annually as far back as 1950 for some countries, yielding 1349 observations of educational attainment, sectoral employement, and sectoral productivity.

Figure 1 illustrates the dual economy structure found in the data. There is a clear negative correlation between the share of the population employed in agriculture and the ratio of agricultural labor productivity to nonagricultural labor productivity. Each dot represents a country in a given year, and the relationship therefore seems to have been fairly stable since the middle of the 20th century. As of 2005, the agricultural labor productivity gap was closed in Northern Europe and the United States, whereas agricultural productivity was just 10-20 percent of nonagrarian productivity in several Asian and African nations. ${ }^{5}$ Closing the sectoral productivity gap in the latter group of countries (alternatively, lowering the employment share in agriculture to rich-country levels) would therefore have a huge impact on their aggregate income levels.

The most dual economies in terms of the agricultural labor productivity gap are also the economies with the least educated labor force. This is no surprise since it is well known that the educational attainment of the workforce and aggregate income is positively correlated. A more interesting question is whether there is a link between the sectoral allocation of skilled workers and relative sectoral productivity levels. My data set does not offer an answer, but Gollin et al. (2011) find that people employed outside agriculture in developing countries has twice as long an education as their compatriots working in the fields. Africa has the highest ratio of 2.8. In Denmark, the country with the highest relative agricultural productivity level as of 2005, the ratio is about 1.1, meaning that agricultural workers and nonagricultural workers have almost the same education level. ${ }^{6}$ The urban/rural skill gap thus seems to be correlated with the agricultural labor productivity gap. This does of course not imply causality by itself,

\footnotetext{
${ }^{4}$ See appendix for the full list. Countries with no agricultural sector (i.e., Hong Kong and Singapore) are removed from the sample. Educational attainment data is only available at five-year intervals, so a linear interpolation is used to fill the gaps.

${ }^{5}$ Some of this difference may be attributed to the type of goods produced. Mechanized agriculture based on wheat or animal products is likely to be more skill intensive than agriculture specialized in crops that require manual harvesting (e.g., fruits and vegetables).

${ }^{6} 14.0$ years versus 12.9 years. Source: Statistics Denmark, table KRHFU2, and author's calculations.
} 


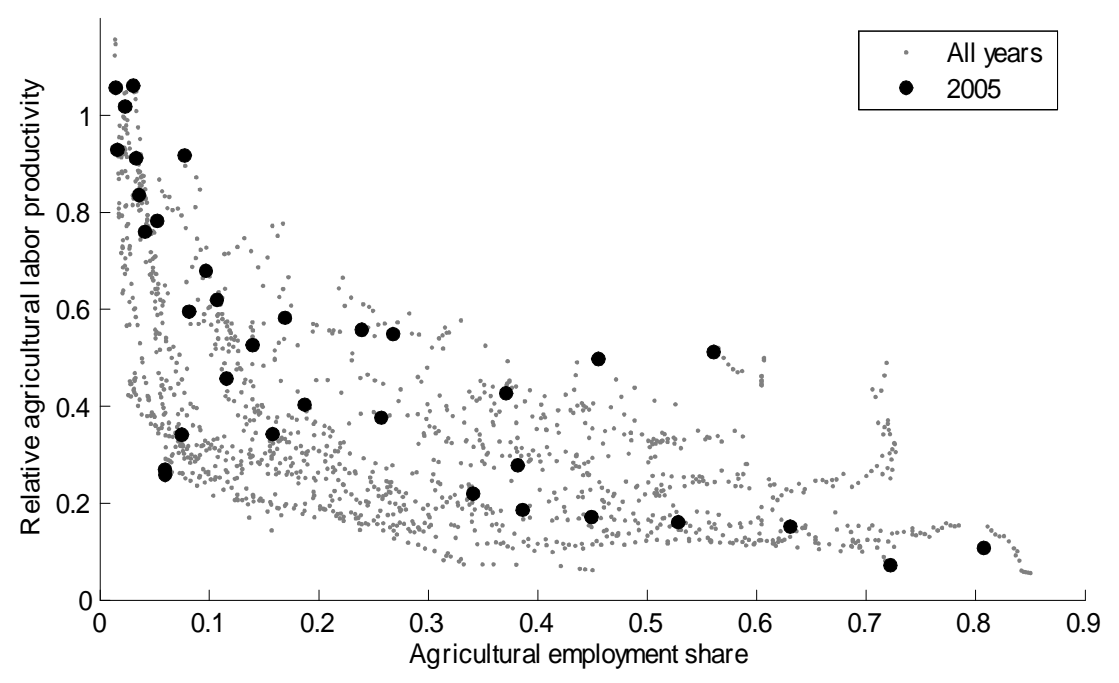

Figure 1: The dual economy

but several empirical studies have shown that education is indeed an important determinant of technology adoption. ${ }^{7}$ Moreover, as casual observation will attest, the methods of production employed by illiterate subsistence farmers in developing countries are very different from those found in the highly mechanized agriculture in, for example, the American Midwest.

If one accept the idea that skilled workers are crucial to adoption of modern agricultural practices, then explaining the dual economy is eqiuvalent to explaining the sectoral allocation of skilled workers. The model presented in the next section does exactly that.

\section{The Model}

There are two types of workers in the economy: high skilled $H$, and low skilled $L$. The supplies of the two labor types are fixed and exogenous. The aggregate labor supply is normalized to unity such that $H$ and $L$ are equal to the shares of high and low skilled workers in the total population. Skilled workers have the ability to operate the newest technology in production, giving firms or farms employing them a relative productivity level $A>1$. Furthermore, skilled workers can carry out unskilled work, but unskilled workers are not employable in skill intensive

\footnotetext{
${ }^{7}$ See Huffman (2001) for a survey.
} 
jobs. When high skilled workers are employed in low skill jobs, however, they are assumed to lose their productivity advantage. ${ }^{8}$

The economy consists of two sectors: manufacturing (the modern sector) and agriculture (the traditional sector). Labor inputs and outputs in the two sectors are labelled with subscript $M$ and $A$ respectively. The structure of the workforce implies the following labor market equilibrium conditions:

$$
\begin{gathered}
H_{A}+H_{M} \leq H, \\
L_{A}+L_{M} \geq L, \\
H+L=1 .
\end{gathered}
$$

Aggregate production in the manufacturing sector is given by:

$$
Y_{M}=A K^{\alpha}\left(H_{M}^{\gamma} L_{M}^{1-\gamma}\right)^{1-\alpha}, 0<\alpha<1,0<\gamma<1 .
$$

Agricultural workers operate their own individual farms using a Cobb-Douglas technology with land and labor as inputs. Land, denoted $X$, is in fixed supply, and agricultural production is assumed to exhibit diminishing returns to labor.

$$
\begin{gathered}
Y_{A}^{H}=A X_{H}^{\beta} H_{A}^{1-\beta}, \\
Y_{A}^{L}=X_{L}^{\beta} L_{A}^{1-\beta}, \\
X_{H}+X_{L}=X .
\end{gathered}
$$

I abstract from capital in the agricultural sector for simplicity, and because my qualitative results are unaffected by its absence. The allocation of land between workers follows from

\footnotetext{
${ }^{8} A$ should therefore be thought of as a Hicks neutral technology level, not a labor augmenting productivity parameter.
} 
profit maximization. Skilled workers will operate larger farms, and the agricultural sector is therefore reminicent of the Adamopoulos and Restuccia (2011) model where heterogenous productivity levels of farm owners create dispersion in farm sizes. Aggregating across farms yields an agricultural production function in which skilled and unskilled labor are perfect substitutes:

$$
Y_{A}=Y_{A}^{H}+Y_{A}^{L}=X^{\beta}\left(A^{\frac{1}{1-\beta}} H_{A}+L_{A}\right)^{1-\beta} .
$$

As it can be seen above, the elasticity of substitution between skilled and unskilled workers in agriculture is infinite, whereas it is equal to one in the manufacturing sector. These numbers are mainly chosen to keep the algebra simple, but they do not seem unreasonable. ${ }^{9}$ In any case, the qualitative predictions of the model are robust to the choice of elasticities as long as the one in agriculture is bigger than the one in manufacturing.

The economy is small and open, both goods are tradable, and capital is internationally mobile. ${ }^{10}$ Prices and the interest rate are therefore determined exogenously by the world market. The basic mechanism of the model is not affected by this assumption, but it is convenient to work with an open economy since it eliminates the need to take a stand on preferences. The price of agricultural goods is chosen as numeraire and the relative price of manufactured goods is $p .{ }^{11}$ Profit maximization yields the following skill premia in the two sectors:

$$
\frac{w_{M}^{H}}{w_{M}^{L}}=\frac{\gamma}{1-\gamma} \frac{L_{M}}{H_{M}}
$$

\footnotetext{
${ }^{9}$ Emprical estimates of the aggregate elasticity of substitution between skilled and unskilled workers usually fall in the 1.3-1.5 range. See e.g., Johnson (1970), Fallon and Layard (1975), Katz and Murphy (1992), Katz and Murphy (1992), Ciccone and Peri (2005). Krusell et al. (2000) arrive at a somewhat higher estimate of 1.66. These empirical elasticities are based on North American data (except Fallon and Layard (1975)) and can therefore be regarded as estimates for the modern sector.

${ }^{10}$ Caselli and Feyrer (2007) show that the financial rate of return is roughly equal across countries, so international capital mobility is not an unreasonable assumption.

${ }^{11}$ Equivalently, $p$ can be thought of as a productivity advantage in manufacturing.
} 


$$
\frac{w_{A}^{H}}{w_{A}^{L}}=A^{\frac{1}{1-\beta}},
$$

where $w_{j}^{i}$ is the wage in sector $j$ for labor type $i$. Note that the skill premium in manufacturing is related to labor inputs, whereas it is determined by the technology level in agriculture. This difference is crucial to the allocation of labor. Only the manufacturing sector will attract skilled workers for sufficiently low levels of $H$. Increasing $H$ will decrease the wage rate for skilled workers through a supply effect and increase the wage rate for unskilled workers because of the skill complementarity in the manufacturing sector. These wage effects cause migration of workers between sectors, and we end up with three cases: one where unskilled labor is employed in both sectors and skilled workers in manufacturing only, one where both types of labor are employed in both sectors, and finally one where skilled workers are employed in both sectors and unskilled workers in agriculture only. On top of these three, there is a fourth case where the stock of educated workers is so large that the skill premium would become negative if they all were to be employed in skill intensive jobs. This would not be rational, and some of them will choose to be employed in low skill jobs instead, thereby keeping the skill premium at zero.

\section{Case I: skilled and unskilled workers in both sectors}

If both classes of workers are employed in both sectors, then $w_{M}^{H}=w_{A}^{H}$ and $w_{M}^{L}=w_{A}^{L}$, and no high skilled workers will perform unskilled work since the skill premium in agriculture is strictly positive. The first order conditions along with labor market equilibrium imply:

$$
w_{M}^{H}=w_{A}^{H} \Longleftrightarrow L_{A}=\lambda-A^{\frac{1}{1-\beta}} H_{A}
$$

where $\lambda \equiv\left(\frac{(1-\beta)}{p(1-\alpha) \gamma^{\gamma}(1-\gamma)^{1-\gamma}}\left(\frac{r}{\alpha}\right)^{\frac{\alpha}{1-\alpha}} A^{\frac{\gamma}{1-\beta}-\frac{1}{1-\alpha}}\right)^{\frac{1}{\beta}} X$. It follows from the labor market equilibrium conditions that:

$$
\begin{gathered}
L_{A}=(1-\gamma)\left\{\lambda-A^{\frac{1}{1-\beta}}+\left(A^{\frac{1}{1-\beta}}+\frac{\gamma}{1-\gamma}\right) L\right\}, \\
H_{A}=\left((1-\gamma)+\frac{\gamma}{A^{\frac{1}{1-\beta}}}\right) H+\frac{\gamma}{A^{\frac{1}{1-\beta}}}(\lambda-1) .
\end{gathered}
$$


Define $\underline{H}$ as the lowest possible share of skilled workers for which no skilled workers are employed in agriculture. Likewise, define $\bar{H}$ as the lowest possible share of skilled workers for which no unskilled workers are employed in agriculture. The expressions above yield:

$$
\underline{H}=\frac{\gamma(1-\lambda)}{A^{\frac{1}{1-\beta}}(1-\gamma)+\gamma} \quad, \quad \bar{H}=\frac{(1-\gamma)\left(A^{\frac{1}{1-\beta}}-\lambda\right)}{A^{\frac{1}{1-\beta}}(1-\gamma)+\gamma} .
$$

The number of high and low skilled agricultural workers can be written in terms of these cut-off values:

$$
\begin{aligned}
& H_{A}=\left((1-\gamma)+\frac{\gamma}{A^{\frac{1}{1-\beta}}}\right)(H-\underline{H}), \\
& L_{A}=\left(A^{\frac{1}{1-\beta}}(1-\gamma)+\gamma\right)(L-\bar{H}) .
\end{aligned}
$$

The allocation of workers in the manufacturing sector follows directly from the labor market equilibrium conditions.

\section{Case II: no skilled workers in agriculture}

All high skilled workers will be employed in manufacturing if $H \leq \underline{H}$, meaning that $H_{M}=$ $H$ and $H_{A}=0$. The allocation of unskilled wokers is implicitly given by the labor market equilibrium condition:

$$
w_{M}^{L}=w_{A}^{L} \Longleftrightarrow \frac{L_{A}^{\beta}}{L_{M}^{\gamma}}=\frac{1-\beta}{(1-\alpha)(1-\gamma)} \frac{1}{p A^{\frac{1}{1-\alpha}}\left(\frac{\alpha}{r}\right)^{\frac{\alpha}{1-\alpha}}} \frac{\bar{X}^{\beta}}{H^{\gamma}} .
$$

\section{Case III: no unskilled workers in agriculture, strictly positive skill premium}

The marginal product of unskilled workers, and thus pay, is higher in manufacturing than in agriculture when $H>\bar{H}$. No unskilled workers will therefore choose to work in the agrarian sector, meaning that $L_{A}=0$ and $L_{M}=L$. It follows that:

$$
w_{M}^{H}=w_{A}^{H} \Longleftrightarrow \frac{H_{A}^{\beta}}{\left(H-H_{A}\right)^{1-\gamma}}=\frac{1-\beta}{(1-\alpha) \gamma p}\left(\frac{r}{A \alpha}\right)^{\frac{\alpha}{1-\alpha}} \frac{\bar{X}^{\beta}}{(1-H)^{1-\gamma}} .
$$

Case IV: no unskilled workers in agriculture, zero skill premium 
As argued above, skilled workers will move into low skill jobs when $H$ increases beyond the point where the skill premium hits zero. This has the additional effect that it caps the number of agricultural workers as diminishing returns otherwise would push agricultural wages below that of unskilled labor in manufacturing. A zero skill premium therefore implies:

$$
\frac{w_{H}^{M}}{w_{L}^{M}}=\frac{\gamma}{1-\gamma} \frac{L_{M}}{H_{M}}=1 \Longleftrightarrow H_{M}=\frac{\gamma}{1-\gamma} L_{M} .
$$

Let $H_{A}^{\max }$ denote the upper bound for skilled workers in agriculture. By using the expression above along with the labor market equilibrium conditions, this upper cound can be found as $H_{A}^{\max }=\lambda A^{1-\frac{\gamma}{1-\beta}}$. Moreover, since the marginal products of the two types of labor in manufacturing are equal, their proportions are pinned down by the elasticities $\gamma$ and $1-\gamma$ :

$$
\begin{gathered}
H_{M}=\gamma\left(1-H_{A}^{\max }\right), \\
L_{M}=(1-\gamma)\left(1-H_{A}^{\max }\right) .
\end{gathered}
$$

\section{Calibration}

The model is parameterized as shown in table 4. $\alpha$ and $\beta$ are chosen such that the labor income shares are identical and equal to two thirds in both sectors. ${ }^{12} p$ is set to unity to ensure that any sectoral productivity gap is generated endogenously. The remainder of the parameters are calibrated such that a model economy with a very high $H$ resembles the United States. The numbers are taken from the data set described in section 2 unless stated otherwise.

- $\gamma$ is not just an elasticity, but also the optimal share of skilled workers in an economy with no agriculture. This parameter is therefore chosen to match the U.S. high school graduation rate, which has stabilized around $0.75 .^{13}$

\footnotetext{
${ }^{12}$ As discussed in Vollrath (2009a) and Gollin et al. (2011), there is no empirical basis for believing that the dual economy arises from sectoral differences in labor income shares.

${ }^{13}$ Goldin (1999), Heckman and LaFontaine (2007).
} 


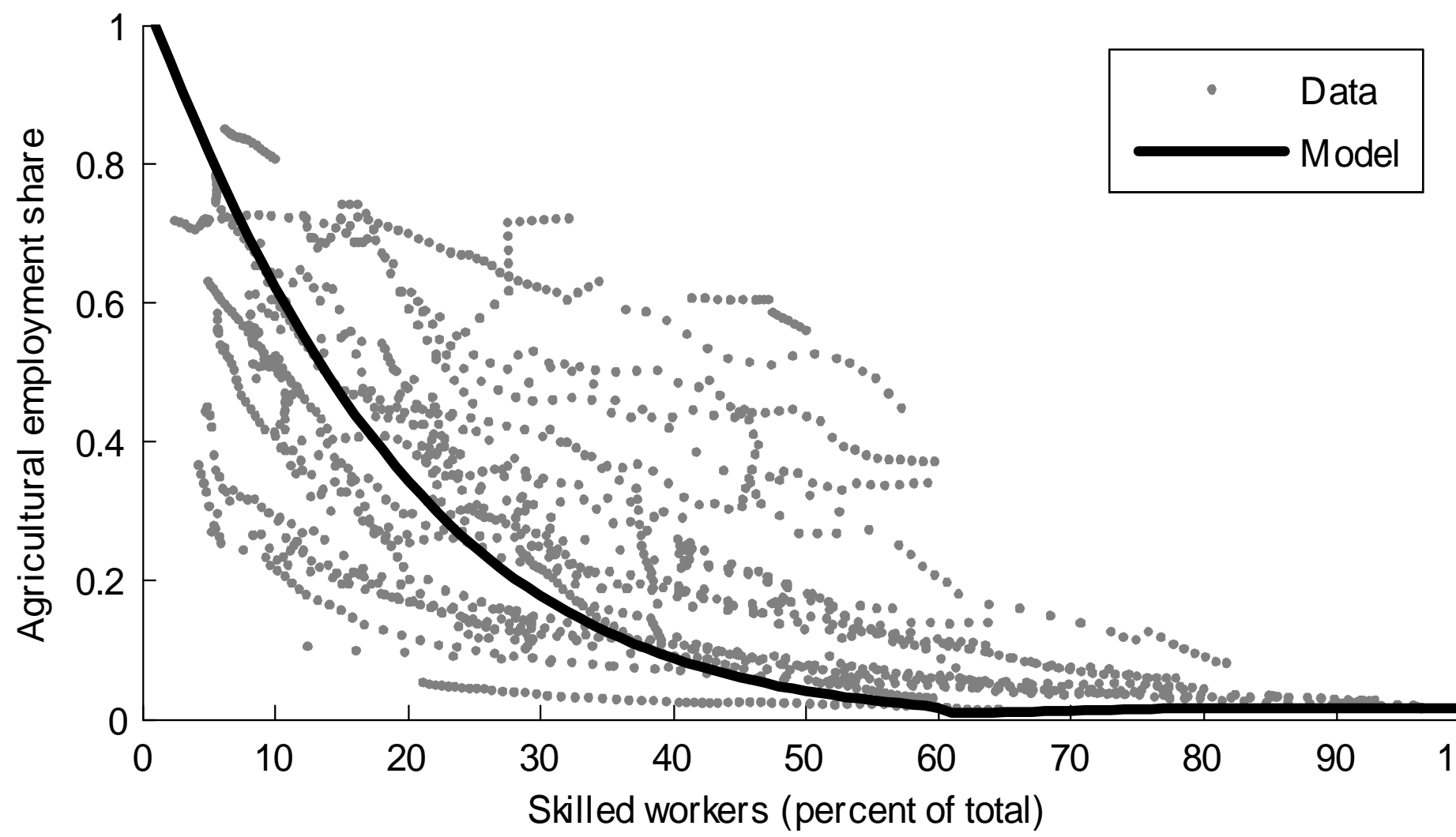

- The interest rate, $r$, is set to 0.08 per year reflecting the average annual return on the S\&P 500 equity index since 1970.

- The productivity level, $A$, is related to the skill premium in agriculture through the expression $\frac{w_{A}^{H}}{w_{A}^{L}}=A^{\frac{1}{1-\beta}}$. Skilled workers in the U.S., defined as having more than eight years of education, have on average spend seven years more in school than unskilled workers. Combined with a Mincerian return to education of 0.1 per year, this gap implies that $\frac{w_{A}^{H}}{w_{A}^{L}}=2$, and, in turn, that $A=1.6$.

- The land variable, $X$, is chosen to ensure that the share of agriculture in GDP is equal to $1.5 \%$ for a country with $H=1$.

As shown in an appendix, the results of the next section are robust to the calibration as long as the parameters are chosen within empirically plausible bands. 


\begin{tabular}{|c|c|c|c|c|c|c|}
\hline$\alpha$ & $\beta$ & $\gamma$ & $p$ & $r$ & $A$ & $X$ \\
\hline \hline$\frac{1}{3}$ & $\frac{1}{3}$ & 0.75 & 1 & 0.08 & 1.6 & 0.05 \\
\hline
\end{tabular}

\section{$5 \quad$ Predictions and Empirical Evidence}

The relationship betweeen labor productivity (i.e., output per worker) and the share of skilled workers in the labor force predicted by the model is shown in figure 2. Agricultural productivity trails that of manufacturing when the share of skilled workers is low. As shown in figure 3, this coincides with the agrarian sector being relatively large, and aggregate productivity is therefore low. The model outcome is therefore consistent with the empirical findings outlined in the introduction to this paper.

The sectoral productivity gap persists for intermediate levels of educational attainment, but aggregate productivity catches up as the manufacturing sector carries more weight. Diminishing returns combined with fewer workers is the only reason why agriculture does not fall more behind. However, agricultural labor productivity grows swiftly when the share of skilled workers has passed the turning point $\underline{H}$ where they start to flow from manufacturing to the agrarian sector. In fact, it overtakes manufacturing briefly, but declines again due to diminishing returns. ${ }^{14}$

Figure 4 compares the predicted link between the share of skilled workers and relative agricultural labor productivity to what we see empirically. Skilled workers are in the data defined as people with at least some secondary education. ${ }^{15}$ The fit is not perfect, but the positive theoretical relationship do indeed exist empirically. The model predicts that labor productivity in agriculture should be around around one third of the level in nonagriculture in economies with few skilled workers, which is somwhat higher than in the data. However, Gollin et al. (2011) adjust sectoral productivity for various factors related to labor input (e.g., hours, quality of schooling, cost of living) and find that relative agricultural productivity in

\footnotetext{
${ }^{14}$ This overshooting is to some degree an artifact of the simple two-sector structure of the model. Including, say, a service sector that could absorb some of the skilled workers would change this result.

${ }^{15}$ This is consistent with Barro (2000) who finds that only the stock of workers with secondary education or more has a significant effect on growth.
} 


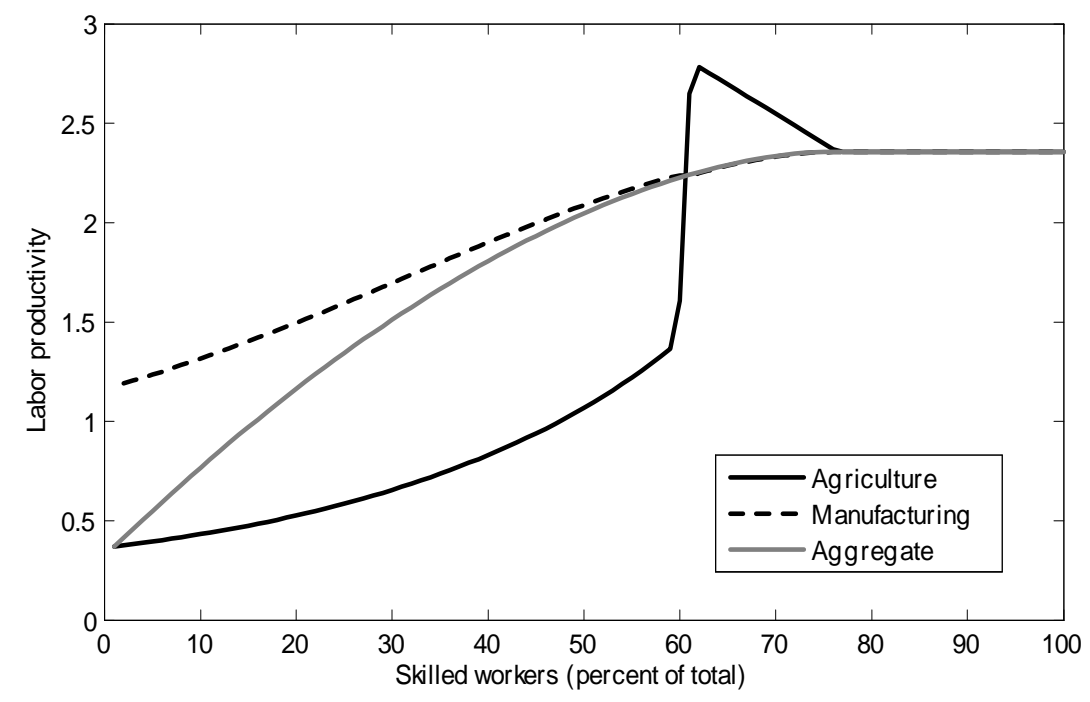

Figure 2: Skilled workers and sectoral labor productivity

low income countries is likely to be around 0.5 rather than the 0.25 they find in their raw data. Vollrath (2010) arrives at a similar conclusion. Applying an adjustment of the same magnitude to my data set will put the observed productivity gap in the same ballpark as the one predicted by the model.

Total factor productivity in the manufacturing sector is simply given by $p A$ in the model, and therefore equal to 1.6 with the current parameterization. In agriculture, TFP is dependent on the share of high skilled workers in the sector:

$$
T F P_{A}=\left(\frac{A^{\frac{1}{1-\beta}} H_{A}+L_{A}}{H_{A}+L_{A}}\right)^{1-\beta} .
$$

$T F P_{A}=A$ when only skilled workers are employed in agriculture, and it becomes equal to TFP in the manufacturing sector by assumption since $p=1$. In the polar case where only unskilled workers are present in agriculture, $T F P_{A}=1$. Countries endowed with many skilled workers therefore have a TFP level in agriculture that is 60 percent higher than in countries with few skilled workers.

A few other implications of the model are worth noticing. First, average farm size is inversely proportional to the employment share in agriculture, and farm sizes consequently 


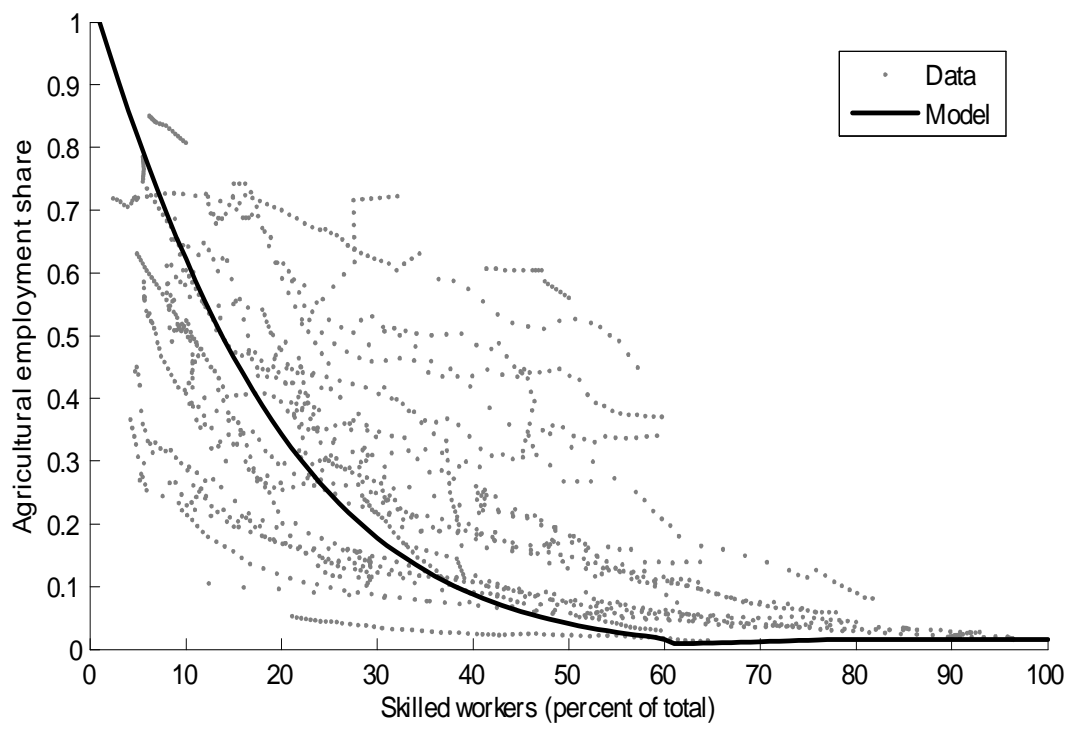

Figure 3: Agricultural employment share

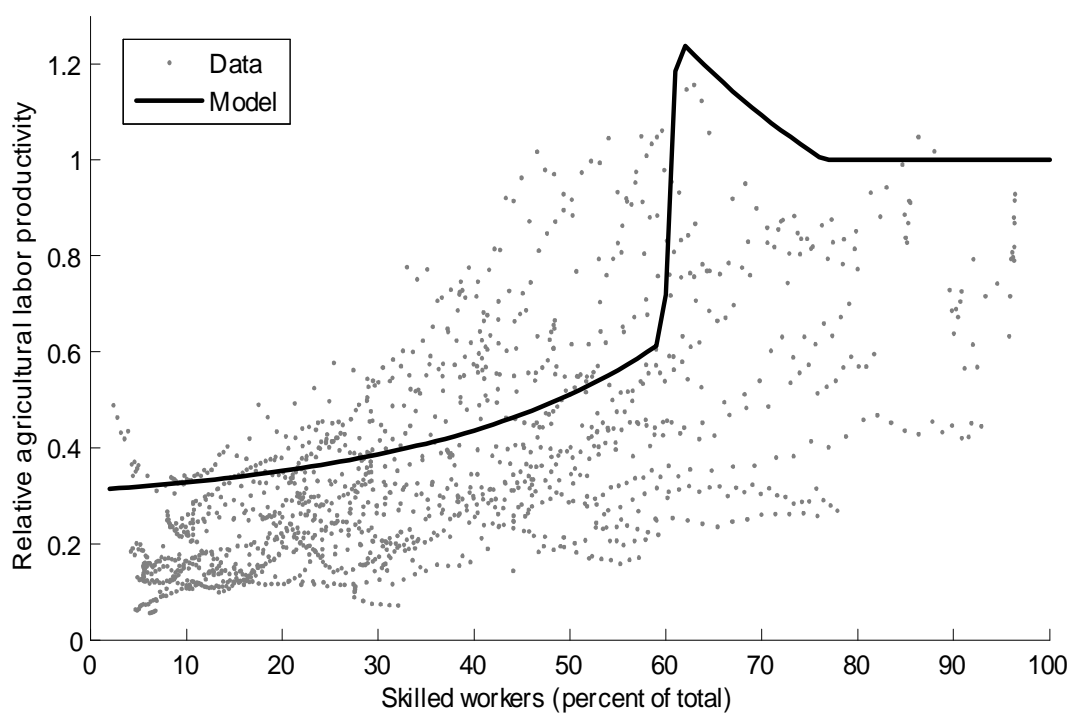

Figure 4: Skilled workers and the agricultural labor productivity gap 
increase with development. Adamopoulos and Restuccia (2011) find the same pattern in a cross section of countries. Second, whereas output per agricultural worker increases with development, output per acre falls. This is consistent both with Adamopoulos and Restuccia (2011) and with a comprehensive study of U.S. agriculture over the past two centuries by Mundlak (2005). Third, the increase in agricultural TFP following an inflow of high skilled workers happens in the model when the agricultural employment share is low. Again, this fits well with the experience of the U.S. TFP in agriculture was relatively stable prior to World War II, but grew rapidly in the second half of the 20th century when the agricultural employment share had dropped below 10 percent. ${ }^{16}$ Moreover, as in the model, labor productivity had started to rise much earlier than TFP as the declining workforce increased the land-to-labor ratio.

\section{Taking Stock}

I have in this paper developed a model in which sector sizes, sectoral productivity levels and aggregate output are pinned down by the share of skilled workers in the labor force. ${ }^{17}$ The dual economy phenomenon arises in countries with low levels of human capital because workers with different skill levels are more complementary in manufacturing than in agriculture. No frictions are imposed on the economy in order to arrive at this result. Calibrated to the United States, the model is able to generate sectoral productivity gaps and employment patterns similar to what is found empirically in low and middle-income countries. Admittedly, the productivity gap predicted by the model is somewhat smaller than in the group of very poor countries, but this may in part be due to a well known downward bias in estimated agricultural productivity.

While the model mimics sectoral patterns quite successfully, it conforms less well with aggregate income differences across countries. A high skill country in the calibrated version of the model is about six times richer than a country with no educated workers (see figure 2). In comparison, value added per worker in the United States was in 2005 about 52 times

\footnotetext{
${ }^{16}$ Mundlak (2005).

${ }^{17} \mathrm{~A}$ corrolary of this result is that the debate about whether agriculture or the modern sector is the main driver of the development process may be misguided. See Gollin (2010) for a survey of the debate.
} 
higher than in Malawi, the poorest country in my sample. This discrepancy arises from the assumption that all countries have the same productivity level in manufacturing. In reality, nonagriculture value added per worker was 14 times larger in the United States than in Malawi.

The productivity gap observed across countries within the modern sector naturally gives rise to the question of whether skill complementarity plays a role there as well. It is certainly a possibility since different types of modern industries need different skill inputs. Software development, say, is likely to require more workers with tertiary education than textile production does. An extension of the model with more sectors and more skill levels will therefore be able to generate greater income differences across countries.

All things considered, skill complementarity has the potential to be a simple and empirically relevant explanation for the dual economy phenomenon, and indeed for global inequality more broadly. An implication of this observation is that education may play an even more important role in development than what is currently believed to be the case today. Moreover, the absence of frictions in the model imply that the dual economy may be a Pareto optimal equilibrium outcome. This is not to say that factor market distortions or externalities necessarily are unimportant in the dual economies of the real world, or that government intervention is pointless. But the inefficiencies that need to be adressed by policy makers may be a lot smaller that what a benchmark model without sectoral differences in skill complementarity would suggest. 


\section{Appendix A: Data Availability}

\begin{tabular}{llll}
\hline Country & Years & Country & Years \\
\hline \hline Argentina & $1950-2005$ & Mauritius & $1990-2005$ \\
Bolivia & $1950-2005$ & Malawi & $1990-2005$ \\
Brazil & $1950-2005$ & Malaysia & $1975-2005$ \\
Chile & $1950-2005$ & Netherlands & $1960-2005$ \\
China & $1990-2005$ & Peru & $1960-2005$ \\
Colombia & $1950-2005$ & Phillipines & $1975-2005$ \\
Costa Rica & $1950-2005$ & Senegal & $1990-2005$ \\
Denmark & $1950-2005$ & South Africa & $1990-2005$ \\
Spain & $1960-2005$ & South Korea & $1965-2005$ \\
France & $1955-2005$ & Sweden & $1975-2005$ \\
Ghana & $1990-2005$ & Thailand & $1960-2005$ \\
Indonesia & $1975-2005$ & Turkey & $1990-2005$ \\
India & $1960-2005$ & Taiwan & $1965-2005$ \\
Italy & $1955-2005$ & United Kingdom & $1950-2005$ \\
Japan & $1955-2005$ & United States & $1950-2005$ \\
Kenya & $1990-2005$ & Venezuela & $1950-2005$ \\
Mexico & $1950-2005$ & Zambia & $1990-2005$ \\
\hline
\end{tabular}

\section{Appendix B: Sensitivity to the Calibration}

The table below reports the relative agricultural labor productivit and the agricultural employment share predicted by the model for a low income economy $(H=0.1)$ and for a middle income economy $(H=0.4)$. The row labelled "baseline" corresponds to the calibration used in the text. The remaining rows report how the two statistics are affected when a single parameter is changed from the baseline calibration to the value listed in the first column. 


\begin{tabular}{lccccc}
\hline & \multicolumn{2}{c}{ Relative Productivity } & & \multicolumn{2}{c}{ Employment share } \\
\hline \hline \multirow{2}{*}{ Baseline } & $H=0.1$ & $H=0.4$ & & $H=0.1$ & $H=0.4$ \\
\cline { 2 - 3 } \cline { 5 - 6 }$\gamma=\frac{2}{3}$ & 0.33 & 0.44 & & 0.59 & 0.08 \\
$\gamma=\frac{4}{5}$ & 0.40 & 0.57 & & 0.43 & 0.04 \\
$r=0.04$ & 0.31 & 0.37 & & 0.69 & 0.13 \\
$r=0.12$ & 0.35 & 0.43 & & 0.46 & 0.03 \\
$A=1.2$ & 0.38 & 0.46 & & 0.65 & 0.12 \\
$A=2.0$ & 0.31 & 0.49 & & 0.71 & 0.18 \\
\hline
\end{tabular}

\section{References}

Adamopoulos, T. and D. Restuccia (2011). The size distribution of farms and international productivity differences. University of Toronto, Department of Economics Working Paper 441.

Barro, R. J. (2000). Inequality and growth in a panel of countries. Journal of economic growth 5(1), 5-32.

Barro, R. J. and J.-W. Lee (2010). A new data set of educational attainment in the world, 1950-2010. NBER Working Paper No. 15902.

Caselli, F. (2005). Accounting for cross-country income differences. Handbook of Economic Growth 1, 679-741.

Caselli, F. and I. Coleman, Wilbur J. (2001). The us structural transformation and regional convergence: A reinterpretation. Journal of Political Economy 109(3), 584-616.

Caselli, F. and J. Feyrer (2007). The marginal product of capital. The Quarterly Journal of Economics 122(2), 535.

Chanda, A. and C.-J. Dalgaard (2008). Dual economies and international total factor productivity differences: Channelling the impact from institutions, trade, and geography. Economica 75(300), 629-661. 
Ciccone, A. and G. Peri (2005). Long-run substitutability between more and less educated workers: Evidence from us states, 1950-1990. Review of Economics and Statistics 87(4), 652-663.

Fallon, P. and P. Layard (1975). Capital-skill complementarity, income distribution, and output accounting. The Journal of Political Economy, 279-302.

Goldin, C. (1999). A brief history of education in the united states. NBER working paper, Historical Series no. 119 (August 1999).

Gollin, D. (2010). Agricultural productivity and economic growth. Handbook of Agricultural Economics 4, 3825-3866.

Gollin, D., D. Lagakos, and M. E. Waugh (2011). The agricultural productivity gap in developing countries. Mimeo, Arizona State University.

Gollin, D., S. L. Parente, and R. Rogerson (2004). Farm work, home work and international productivity differences. Review of Economic Dynamics 7(4), 827-850.

Gollin, D., S. L. Parente, and R. Rogerson (2007). The food problem and the evolution of international income levels. Journal of Monetary Economics 54 (4), 1230-1255.

Graham, B. S. and J. R. Temple (2006). Rich nations, poor nations: How much can multiple equilibria explain? Journal of Economic Growth 11(1), 5-41.

Hansen, G. D. and E. C. Prescott (2002). Malthus to solow. The American Economic Review 92(4), 1205-1217.

Heckman, J. J. and P. A. LaFontaine (2007). The american high school graduation rate: Trends and levels. NBER Working Paper No. 13670.

Huffman, W. E. (2001). Human capital: Education and agriculture. Handbook of Agricultural Economics 1, 333-381.

Johnson, G. E. (1970). The demand for labor by educational category. Southern Economic Journal, 190-204. 
Katz, L. F. and K. M. Murphy (1992). Changes in relative wages, 1963-1987: Supply and demand factors. The Quarterly Journal of Economics 107(1), 35.

Krusell, P., L. E. Ohanian, J.-V. Ríos-Rull, and G. L. Violante (2000). Capital-skill complementarity and inequality: A macroeconomic analysis. Econometrica 68(5), 1029-1053.

Kuznets, S. S. (1971). Economic Growth of Nations: Total Output and Production Structure. Belknap Press of Harvard University Press.

Landon-Lane, J. S. and P. E. Robertson (2007). Reassessing the impact of barriers to capital accumulation on international income differences. International Economic Review 48(1), $147-154$.

Lucas, Robert E., J. (2004). Life earnings and rural-urban migration. Journal of Political Economy 112(1), 29.

Lucas, Robert E., J. (2009). Trade and the diffusion of the industrial revolution. American Economic Journal: Macroeconomics 1(1), 1-25.

McMillan, M. S. and D. Rodrik (2011). Globalization, structural change and productivity growth. NBER Working Paper No. 17143.

Mundlak, Y. (2005). Economic growth: Lessons from two centuries of american agriculture. Journal of Economic Literature, 989-1024.

Restuccia, D., D. T. Yang, and X. Zhu (2008). Agriculture and aggregate productivity: A quantitative cross-country analysis. Journal of Monetary Economics 55(2), 234-250.

Rodrik, D. (2009). The real exchange rate and economic growth. Brookings Papers on Economic Activity 2008(2), 365-412.

Satchi, M. and J. Temple (2009). Labor markets and productivity in developing countries. Review of Economic Dynamics 12(1), 183-204.

Strulik, H. and J. Weisdorf (2008). Population, food, and knowledge: A simple unified growth theory. Journal of Economic Growth 13(3), 195-216. 
Temple, J. (2005). Dual economy models: A primer for growth economists. The Manchester School 73(4), 435-478.

Temple, J. and L. Wößmann (2006). Dualism and cross-country growth regressions. Journal of Economic Growth 11(3), 187-228.

Vollrath, D. (2009a). The dual economy in long-run development. Journal of Economic Growth 14(4), 287-312.

Vollrath, D. (2009b). How important are dual economy effects for aggregate productivity? Journal of Development Economics 88(2), 325-334.

Vollrath, D. (2010). Measuring aggregate agricultural labor effort in dual economies. Unpublished manuscript. 